\title{
Retraction Note to: Influence of soil-rock mixture and basketball endurance training management based on virtual network mapping
}

\author{
Wenbing $\mathrm{Zhu}^{1}$
}

Published online: 15 November 2021

C) Saudi Society for Geosciences 2021

Retraction Note to: Arabian Journal of Geosciences (2021) 14: 1647 https://doi.org/10.1007/s12517-021-08086-Z

The Editor-in-Chief and the Publisher have retracted this article because the content of this article is nonsensical. The peer review process was not carried out in accordance with the Publisher's peer review policy. The author has not responded to correspondence regarding this retraction.

The original article can be found online at https://doi.org/10.1007/ s12517-021-08086-z.

Wenbing Zhu

zhuwenbing2021@163.com

1 College of Physical Education and Health Science, Chongqing Normal University, Chongqing 401331, China 